\section{REPORT OF THE MEDICAL RESEARCH COUNCIL FOR THE YEAR 1950-5I}

Pp. iv + 214. London: H.M.S.O., 1952. 6s.

This report begins by paying tribute to the late Lord Addison who, since 1948, was chairman of the Medical Research Council with which he had so long and so intimately been associated.

The report contains lists of the staffs of all the Council's research units and also a list of over a thousand publications by/members of the staff and grant-holders. The review of the year's work makes impressive reading. It includes studies on the structure of proteins, work on pertussis vaccines, the bacteriology of infantile gastro-enteritis, the trials with B.C.G. and the vole bacillus, investigations on industrial dermatitis and skin grafting, and on problems in ophthalmology. It also includes the work of the statistical research unit, the applied psychological research unit and the tropical research unit at Singapore and also describes investigations on climatological medicine, malaria, antibiotics, insecticides, carcinogenic agents and the action of cortisone and ACTH. Although it may be invidious to pick out the work of any particular group, perhaps special mention should be made of the technique developed for preserving living cells at low temperatures. This has now been successfully carried out with spermatozoa, ovarian tissue, and red blood cells. It is clear that this work opens an enormous new field for research and suggests, what is of tremendous practical importance, that blood for transfusion can now be stored over long periods.

\section{PROSTATECTOMY}

\section{$A$ Method and its Management}

By Professor Charles Wells. Pp. vii + I03, with 72 illustrations. Edinburgh: E. \& S. Livingstone, 1952. 245.

Professor Wells writes with all the vigour of a North Country man who is convinced that what he has to say is right. His method of prostatectomy is that of Wilson Hey, who is well known for having shown that urinary infection after prostatectomy is not inevitable, and this book is a complete guide to this technique. All who have met Wilson Hey will understand how easily those in touch with him soon come to believe that there really is only one way of taking out the prostate, and Professor Wells has fallen under this spell. $\mathrm{He}$ admits that other methods can be used in special centres, but he condemns the nearest rival (retropubic prostatectomy) because he has seen complications in cases that were operated on elsewhere. This is unfair, for who knows what travesty of Millin's operation may have been performed.

This book starts with an historical survey of the development of prostatic surgery leading up to the methods now in use, and the following chapters on pathology, the effects of bladder neck obstruction, its clinical features, investigation, and the indications for treatment are very sound. It would be interesting to hear the comments of some radio- logists if they were asked to do intravenous pyeloz grams on cases of acute retention as a routine is the middle of the night before immediate prose tatectomy could be done.

At this point Professor Wells passes dogmatically? into a maze of controversy almost as if he was unaware that any real problems had ever existed $\frac{1}{5}$ He gives views that depend too often on reason $\overline{\text { s. }}$. that are inadequate to support the inferences $h$. draws from them. For his operation spinal anaes 0 thesia is used because, it is said, of the danger of the inhalation methods, though with modern drugs surely the reverse is true. His aversion to urethral instrumentation is so extreme that he even frowns

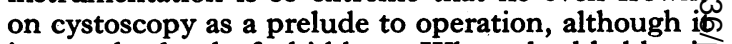
is not absolutely forbidden. When the bladder distended it is often impossible to assess the size of a prostate without cystoscopy, so if this must. not be done the discovery of those conditions $s \oplus^{\circ}$ much better treated by some perurethral methof will be made only after the bladder has been opened. Neoplasms of the bladder, similarly foun by accident, are not always best dealt with incidently to prostatectomy.

The chosen operation is well described in detail and, though it is probably less widely used than the retropubic method in this country, there is no doubt of its excellence in suitable cases. No goog reason is given for using a finger in the rectum? during the removal of the gland, and in a one-stag operation such as this it is not necessary. The fse of any sort of gelatin sponge or oxycel gauze for final haemostasis, as recommended here, will ํㅐㅇㅛ be approved by many urologists, and good result can be obtained without it.

The most remarkable information in this book is found in the statistics. Over 200 consecutivo admissions with prostatic symptoms were treate\& by operation without any of them needing pre $\overrightarrow{\overrightarrow{0}}$ liminary drainage of any sort. In at least two large urological centres elsewhere in England, 20ब similarly consecutive admissions would have ine cluded patients with such other conditions as cardiac failure, uncontrolled diabetes, advanced sen 3 ility with rectal incontinence, gross urinary infections. advanced uraemia, or even all these conditions in the same patient. Some sort of temporary drainage. is essential in these cases, as even this book allows? so what happens to these cases in Liverpool? Preliminary drainage is also usually thought to be necessary in advanced chronic retention with residual urine of 3 pints or more, because the atonic bladder cannot empty properly even afte the obstruction is removed. Professor Wellsos however, forgets his asepsis by recommendingo prostatectomy, without previous drainage, followe by an indwelling urethral catheter for up to three weeks. This is the very type of case on whom to use a Riche's catheter before operation. It is equally astonishing that none of this series of morø than 200 cases needed blood transfusion, eithe? during or after operation, yet most urologists giveo blood as a routine during these operations. Wha $\bar{\phi}$ is the explanation of this? 
This is not a book for any postgraduate who is still working for any higher examination. It contains statements which will surely cause his downfall, and much that will confuse him. It is not even intended that undergraduates should see it at all. The professional prostatectomist, however, is certain to enjoy either his violent opposition to, or alternately, his complete agreement with a surgeon who is much, and equally, respected by both sides, and who has put into this book a lot more wisdom than the present criticisms may suggest.

W.W.W-D.

\section{DISEASES OF THE EAR, NOSE AND THROAT}

By J. Douglas Mclaggan, C.V.O., M.A., M.B., Ch.B., F.R.C.S., and Josephine Collier, M.A., B.M., Ch.B., F.R.C.S. 2nd Edition. Pp. vi +438 , with 194 illustrations. London: H. K. Lewis \& Co. 1952. 37s. 6d.

The authors of this admirable book are certainly to be congratulated on their concise, clear and up-to-date production. The aims set out in the Preface, viz. to serve as a handbook for practitioners, resident house officers and undergraduates, are completely fulfilled, and advances since publication of the first edition in 1937 have been skilfully incorporated.

Well-balanced views are given on topics on which.controversial papers are still pouring forth, such as the use of antibiotics in infections of the ear, nose and throat, sinusitis in children, fenestration for otosclerosis and the danger of tonsillectomy during epidemics of poliomyelitis. The authors do not hesitate to express their opinions dogmatically, e.g. ' the practice of enucleating tonsils to relieve quinsy is dangerous and unsurgical,' and enthusiastic paediatricians might note that 'indiscriminate myringotomy to a tympanic membrane showing slight infection is to be deplored. Opening the mastoid antrum as a method of treatment of gastro-enteritis without obvious signs of middle ear or mastoid disease is unjustifiable.'

Each section of the book commences with a concise account of the surgical anatomy of the region under consideration and continues with methods of examination, diseases and treatment, with a limited description of those operations which students commonly see in their undergraduate days and about which they could be expected to have some understanding at the beginning of an ear, nose and throat appointment.

There is an excellent chapter on allergic diseases of the nose, in which the importance of endocrine and psychogenic factors is emphasized. The indications for removal of tonsils and adenoids receive careful consideration, and no better via media could be enunciated than the statement that "clear views on the value and limitations of the operation are important to ensure that it does not degenerate into a popular remedy for all ailments. Abuse of the operation discredits a valuable form of treatment.'
The illustrations and X-ray photographs are of uniformly high standard, and the book is in every way worthy of the high reputations of its distinguished writers.

\section{A.C.M.}

\section{GYNAECOLOGY}

By Prof. N. Louros (Athens University). Pp. 407. Athens: Greek Publishing Association. 1952. Approximately $£ 7$ is. od.

The book constitutes a supplement to the author's textbook ' Obstetrics,' published in 1948. Its purpose is to provide for the student, the post-graduate student and the general practitioner the necessary background in gynaecology.

The author has attempted to make this book allinclusive, and in this major undertaking he has succeeded. The book is written in the popular Greek language (unusual for a scientific book). It expresses clearly the author's thoughts on his subject and reflects many years of teaching.

The book has 395 text pages of large size. It is well printed. and illustrated with 403 photographs. As a textbook it is divided into three sections.

Section $I$ includes the chapters of embryology, anatomy and physiology of the female body as far as it concerns its reproductive organs and urogenital system. An account is given of the normal female constitutional types.

In the following chapter (normal female development) the author stresses the role of the 'biocatalytics' (hormones, vitamins, enzymes, etc.) in the development of the female body and the normal changes encountered in the uterine mucosa during the different periods of life and menstrual cycle. A brief description of the gynaecological diagnostic procedure and the hygienic measures for a woman is added to this chapter.

Section 2 starts with the reproductive system biocatalytic disturbances and subsequent constitutional and genital disturbances, their aetiology, diagnosis and treatment.

A detailed chapter follows concerning common gynaecological diseases of the female reproductive and urogenital organs, well illustrated with coloured photographs. The last chapter in this section deals with the problem of castration and the prevention of pregnancy. Both sections are comprehensive, clear and include what a general practitioner and/or a student has to know.

Section 3 is devoted to gynaecology and its relevant surgery (techniques, indications, complications and post-operative care).

There is no doubt that this book will be welcomed by students, general practitioners and specialists. I am sure it will also be of great interest to the man of letters who prefers the modern popular Greek scientific language and will thus popularize unknown knowledge!

$$
\text { S. Bissylas, M.D. }
$$

